\title{
A STUDY OF RELATION BETWEEN BODY MASS INDEX AND DYSMENORRHEA AND ITS IMPACT ON DAILY ACTIVITIES OF MEDICAL STUDENTS
}

\section{DIPTI MOHAPATRA*, TAPASWINI MISHRA, MANASI BEHERA, PRIYAMBADA PANDA}

Department of Physiology, IMS \& SUM Hospital, SOA University, Bhubaneswar, Odisha, India. Email: drdiptimohapatra@gmail.com Received: 17 August 2016, Revised and Accepted: 14 September 2016

\section{ABSTRACT}

Objective: Dysmenorrhea is a condition, in which there is a severe, painful, cramping sensation in the lower abdomen which occurs just before or during the menses. It has a major impact on the quality of life and social and occupational roles of females in the society. It also results in insignificant work, school, and college absences in girls. As previous studies have failed to show a definite relation between dysmenorrhea and body mass index (BMI), the aim of our study was to find out an association between BMI and dysmenorrhea among medical students.

Methods: The study was conducted on 200 medical students. Each one was supplied with a questionnaire with detailed menstrual history, family history of dysmenorrhea, and detailed H/O of physical exercise and dietary habits. BMI was calculated by the formula weight in $\mathrm{kg} / \mathrm{height}{ }^{2} \mathrm{in}$ meter, and based on the BMI criteria by the World Health Organization, the students were classified into four groups: Underweight, normal, overweight, and obese groups. The data obtained were statistically analyzed by Pearson Chi-square test, and $\mathrm{p}<0.5$ was considered significant.

Result: From our study, we found out that there is a positive correlation between dysmenorrhea and low BMI.

Conclusion: As there is a positive correlation between BMI and dysmenorrhea, our aim was to educate people about dysmenorrhea and create awareness on diet and dysmenorrhea to assist in improving the quality of life in females.

Keywords: Dysmenorrhea, Body mass index, Quality of life.

(C) 2016 The Authors. Published by Innovare Academic Sciences Pvt Ltd. This is an open access article under the CC BY license (http://creativecommons. org/licenses/by/4. 0/) DOI: http://dx.doi.org/10.22159/ajpcr.2016.v9s3.14753

\section{INTRODUCTION}

Dysmenorrhea is one of the most common health problems in young adolescent girls as it affects $50-90 \%$ of the general population [1]. Dysmenorrhea refers to a cyclical lower abdominal or pelvic pain usually radiating to the back or the thighs, occurring during menstruation. The word dysmenorrhea is derived from the Greek words, "dys" meaning difficult, "meno" meaning month, and "rrhea" meaning flow [2]. It affects the majority of women of reproductive age with $2-29 \%$ having severe pain. Menstrual pain usually starts a day or 2 days before the menstrual flow and tends to cease after 1 or 2 days of menstruation [3] Dysmenorrhea might also be accompanied by nausea, malaise, low back pain, or flank pain [4]. As a debilitating condition, it has a major impact on the quality of life, social, and occupational roles of females. Dysmenorrhea is one of the leading causes of repeated absenteeism in girls from schools and colleges. Data from various studies conducted earlier show that absenteeism from school due to primary dysmenorrhea is $34-50 \%[5,6]$. Dysmenorrhea is divided into two types: Primary dysmenorrhea and secondary dysmenorrhea. Primary dysmenorrhea is the one, in which there is cramping pain in the lower abdomen at the onset of menstruation in the absence of any identifiable pelvic disease; secondary dysmenorrhea, on the other hand, refers to painful menses resulting from an identifiable pelvic pathology such as fibroid, adenomyosis, and pelvic inflammatory disease [7].

There are various reports regarding the impact of body mass index (BMI) on dysmenorrhea $[8,9]$. Several studies have indicated various physiological, cultural, and psychological factors are involved in dysmenorrhea. In addition, in appropriate nutritional diet, lower age, obesity, family history, and reduced frequency of breakfast meals per week are factors affecting the frequency of this problem $[10,11]$. There is a high prevalence of dysmenorrhea in the female of our society; so, it is necessary for us to clarify factors associated with dysmenorrhea in adolescents to improve their quality of life. Hence, the present study was taken up to evaluate the relationship between dysmenorrhea and BMI and its impact on the daily activities of adolescent girls.

\section{METHODS}

The study was carried out in the Postgraduate Department of Physiology of IMS and SUM Hospital, Bhubaneswar. It was a prospective study which included 200 female medical students of the age group 18-20 years, of the same ethnicity and socioeconomic status. Participation by subjects was strictly voluntary. Informed consent was taken from all the students before their participation in the study. Demographic data were collected through standard questionnaire. The questionnaire addressed detailed menstrual history, age at menarche, quantity of menstrual flow, duration of menstrual cycle, severity of pain (dysmenorrhea) and associated symptoms, family history of dysmenorrhea, etc., and detailed $\mathrm{H} / \mathrm{O}$ of physical exercise and dietary habits. BMI was calculated by the formula weight in $\mathrm{Kg} / \mathrm{Height}^{2}$ in meter, and based on the BMI criteria by World Health Organization, the students were classified into four groups: Underweight, normal, overweight, and obese groups. Students with BMI $<18.5$ were considered as underweight, BMI of 18.5-24.9 were considered non-obese or normal, BMI of 25-29.9 were considered overweight and with BMI $>30$ as obese. Data obtained were statistically analyzed by Pearson Chi-square test, and $p<0.5$ was considered significant.

Exclusion criteria were:

- Refusal for participation in the study

- H/O polycystic ovarian diseases

- Pelvic inflammatory diseases

- Ovarian volume $>10$ cc.

\section{RESULTS}

In our study, 200 female medical students were included to evaluate the relationship between BMI and dysmenorrhea and its impact on 
their daily activities. In our study, out of the 200 students studied, dysmenorrhea was present in 148 students and absent in the rest 52 students as shown in Fig. 1.

Fig. 2 shows that $36 \%, 45 \%$, and $19 \%$ patients were suffering from mild (Grade I), moderate (Grade II), and severe dysmenorrhea (Grade III) respectively.

Fig. 3 represents the distribution of the students as per BMI.

Table 1 shows the relation between BMI and dysmenorrhea. It shows that the percentage of students having mild and moderate dysmenorrhea is significantly higher in students having low BMI (underweight students) as compared to overweight and obese students.

Fig. 4 shows the impact of dysmenorrhea on the daily activity of students. Dysmenorrhea results in class absenteeism and college absenteeism along with social withdrawal.

\section{DISCUSSION}

Menstruation is a natural phenomenon in women after puberty and is often associated with dysmenorrhea. Earlier studies have demonstrated an association between BMI and the incidence and severity of dysmenorrhea. Dysmenorrhea usually develops within hours of the beginning of menstruation and increases as flow becomes maximum during $1^{\text {st }}$ or $2^{\text {nd }}$ day. The etiology and pathophysiology of primary dysmenorrhea are not fully known, but most symptoms are by the action of uterine prostaglandins (PG), particularly PGF $2 \alpha$, which are released from the disintegrated endometrial cells as menstruation begins. The PGF2 $\alpha$ stimulates myometrial contractions, ischemia, and sensitization of nerve endings. The evidence of this theory is that women with more severe dysmenorrhea have higher levels of PGF2 $\alpha$ in their menstrual blood.

Some studies have also shown the possible increased levels of leukotrienes and vasopressin [12,13]. There is also the presence of positive family history in case of dysmenorrhea. Several studies have shown increased prevalence of dysmenorrhea in low BMI group $[14,15]$. Low caloric intake, body weight, and fat mass disturb pulsatile secretion of pituitary gonadotrophins leading to an increase in rate of dysmenorrhea. Dysmenorrhea has an impact on their daily activities of adolescent females. In our study, students had symptoms severe enough to cause absenteeism from college and classes (Fig. 4). There is poor academic performance due to inability to concentrate in class and studies, inability to attend classes and tests missed because of absenteeism. Studies also reported social withdrawal from friends, gathering, and sports during menses. In our study, we observed that dysmenorrhea had its impact on the daily activities of girls leading to college absenteeism and inability to pursue routine activities and hobbies, though our values were not statistically significant (Fig. 4). Our study corroborates the study of Svanberg and Ulmsten [16]. Although dysmenorrhea is not life-threatening, it has a profound negative impact on day to day life. This indicates that dysmenorrhea is still an important public health problem [17-19]. Dysmenorrhea primarily affects physical health domain. Psychological parameters such as roleemotional and mental health are probably not affected. These findings are consistent with study by Barnard et al. [5] and Unsal et al. [20]. A longitudinal study by Ju et al. states that a U-shaped association between dysmenorrhea and BMI, revealing increased prevalence in both underweight and overweight females [21]. However, in our study, there was no increased association of the same in the overweight female students (Table 1).

In public health practice, quality of life is acknowledged as an indicator of health [22]. Further, the level of awareness in these future health care professionals is another variable which must be investigated further [23].

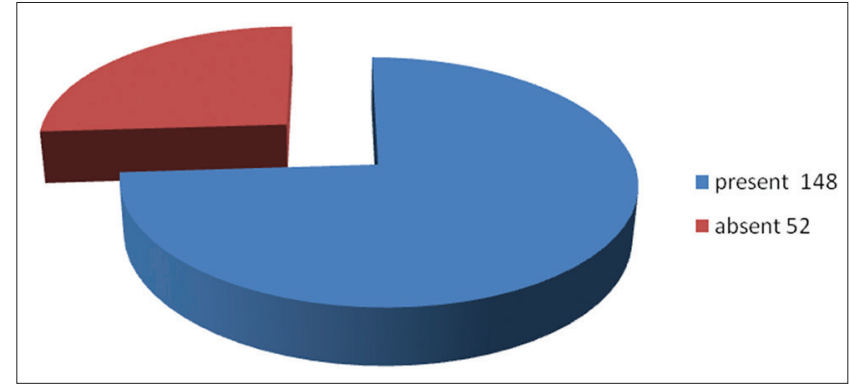

Fig. 1: Percentage of distribution of dysmenorrhea in study group

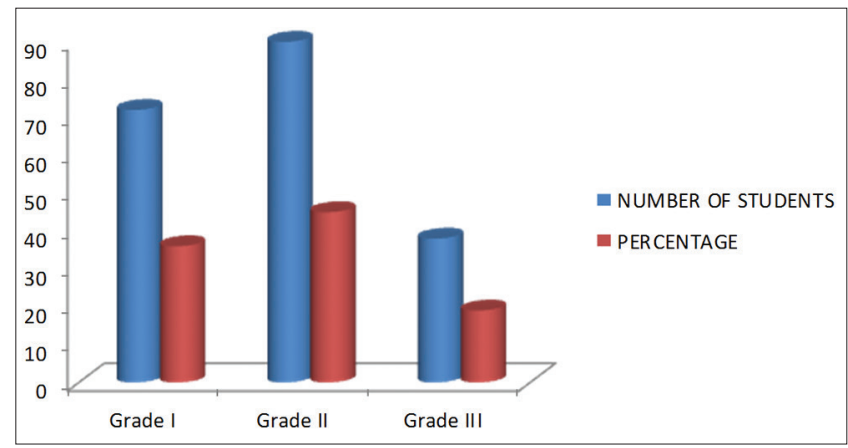

Fig. 2: Distribution of students as per severity of dysmenorrhea

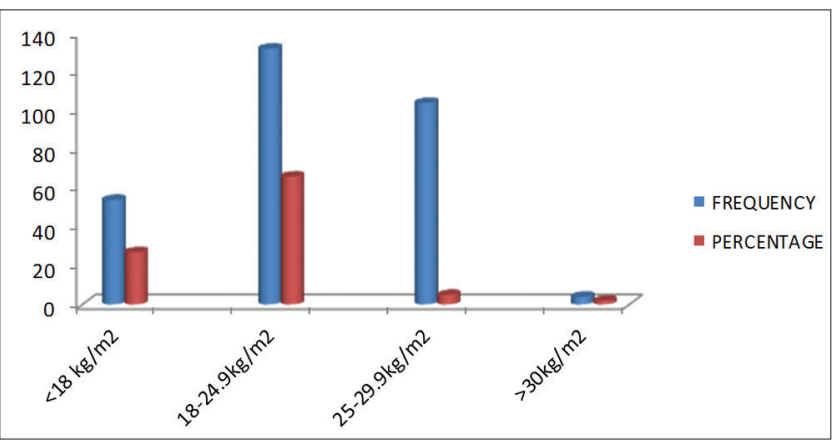

Fig. 3: Distribution of students as per body mass index

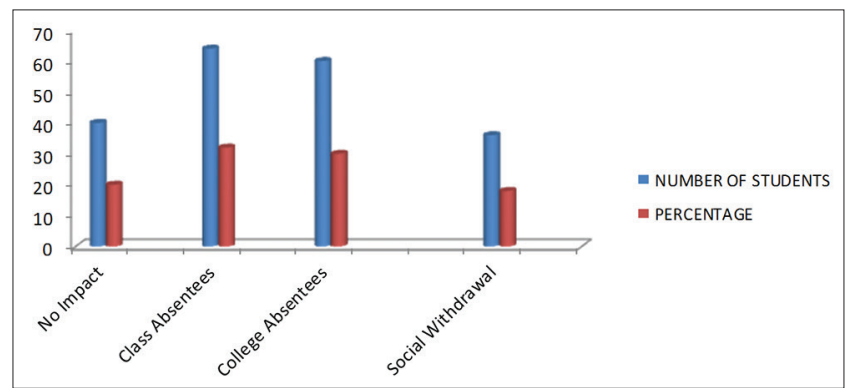

Fig. 4: Impact of dysmenorrhea on daily activity of students

\section{CONCLUSION}

The present study establishes a positive correlation between dysmenorrhea in adolescents and low BMI reflecting their poor dietary intake. Hence, intake of balanced diet will assist them in improving quality of life and enabling them to mature into more socially and economically productive members of the society. Dysmenorrhea has a negative effect on health-related quality of life. It is a leading cause of school and college absenteeism. Dysmenorrhea is an important public health problem, so attempt must be made to find out the cause 
Table 1: Relationship between BMI and dysmenorrhea

\begin{tabular}{llll}
\hline BMI in $\mathbf{~ k g} / \mathbf{m}^{2}$ & Mild dysmenorrhea (n=72) & Moderate dysmenorhea (n=90) & Severe dysmenorrhea (n=38) \\
\hline$<18$ (underweight) & $18 \%$ & $70 \% \%^{*}$ & $76 \% *$ \\
$18-24.9$ (normal weight) & $32 \%$ & $22 \%$ & $18 \%$ \\
$25-29.9$ (overweight) & $46 \%$ & $8 \%$ & $6 \%$ \\
$>30$ (Obese) & $4 \%$ & $0 \%$ & $0 \%$ \\
\hline
\end{tabular}

*p<0.05. BMI: Body mass index

of dysmenorrhea and provide health education so as to improve the quality of life in adolescent females.

\section{REFERENCES}

1. Margaret A, Manjubala D. Relationship between BMI (body mass index) and dysmenorrhea among adolescents in a college of nursing at Puducherry, India. Int Res J Med Sci 2016;4(3):4-6.

2. Chauhan M, Kala J. Relation between dysmenorrhea and body mass index in adolescents with rural versus urban variation. J Obstet Gynaecol India 2012;62:442-5.

3. Ju H, Jones M, Mishra G. The prevalence and risk factors of dysmenorrhea. Epidemiol Rev 2014;36:104-13.

4. Khodakarami B, Masoomi SZ, Faradmal J, Nazari M, Saadati M, Sharifi F, et al. The severity of dysmenorrhea and its relationship with body mass index among female adolescents in Hamadan, Iran. J Midwifery Reprod Health 2015;3(4):444-50.

5. Barnard K, Frayne SM, Skinner KM, Sullivan LM. Health status among women with menstrual symptoms. J Womens Health (Larchmt) 2003;12(9):911-9.

6. Bettendorf B, Shay S, Tu F. Dysmenorrhea: Contemporary perspectives Obstet Gynecol Surv 2008;63(9):597-603.

7. Berek JS. Berek and Novak's Gynecology. $15^{\text {th }}$ ed. Philadelphia: Lippincott, Williams \& Wilkins; 2011.

8. Gibbs RS, Karlan BY, Haney AF, Nygaard IE. Danforth's Obstetrics and Gynecology. $10^{\text {th }}$ ed. Philadelphia: Lippincott, Williams \& Wilkins; 2008.

9. Schuiling KD, Likis FE. Women's Gynecologic Health. $2^{\text {nd }}$ ed Massachusetts: Jones \& Bartlett Learning; 2011.

10. Salmalian H, Saghebi R, Moghadamnia AA, Bijani A, Faramarzi M, Nasiri Amiri F, et al. Comparative effect of thymus vulgaris and ibuprofen on primary dysmenorrhea: A triple-blind clinical study. Caspian J Intern Med 2014;5:82-8.

11. Eittah HF. Effect of breakfast skipping on young females' menstruation.
Health Sci J 2014;8(4):469-84.

12. Wallace S, Keightley A, Gie C. Dysmenorrhoea. Obstet Gynaeco 2010;12:149-54.

13. Akerlund M, Strömberg P, Forsling ML. Primary dysmenorrhoea and vasopressin. Br J Obstet Gynaecol 1979;86(6):484-7.

14. Hirata M, Kumabe K, Inove Y. Study of relation between frequency of menstrual pain and body weight in female adolescents. Nippon Koshu Eisei Zasshi 2002;49:516-24.

15. Tangchai K, Titapant V, Boriboonhirunsarn D. Dysmenorrhea in Thai adolescents: Prevalence, impact and knowledge of treatment. J Med Assoc Thai 2004;87 Suppl 3:S69-73.

16. Svanberg L, Ulmsten U. The incidence of primary dysmenorrhea in teenagers. Arch Gynecol 1981;230(3):173-7.

17. Patel V, Tanksale V, Sahasrabhojanee M, Gupte S, Nevrekar P. The burden and determinants of dysmenorrhoea: A population-based survey of 2262 women in Goa, India. BJOG 2006;113(4):453-63.

18. Roth Iisgkeit A, Thyen U, Stoven H, Schwarzenberger J, Schmucker P. Pain among children and adolescents: Restrictions in daily living and triggering factors. Pediatrics 2005;115:152-62.

19. Banikarim C, Chacko MR, Kelder SH. Prevalence and impact of dysmenorrhea on Hispanic female adolescents. Arch Pediatr Adolesc Med 2000;154(12):1226-9.

20. Unsal A, Ayranci U, Tozun M, Arslan G, Calik E. Prevalence of dysmenorrhea and its effect on quality of life among a group of female university students. Ups J Med Sci 2010;115(2):138-45.

21. Ju H, Jones M, Mishra GD. A U-shaped relationship between body mass index and dysmenorrhea: A longitudinal study. PLoS One 2015;10(7):e0134187.

22. Puri S, Singh A. Adam and AMS scale for assessing andropause. Among aging Indian men. Int J Pharm Pharm Sci 2015;7(1):453-58.

23. Nagashekhara M, Anil T, Kiran CN. Study of premenstrual syndrome among future healthcare professionals in Masterskill Global College. Int J Pharm Pharm Sci 2016;8(2):66-71. 